\title{
Feasibility and acceptability of brief individual interpersonal psychotherapy among university students with mental distress in Ethiopia
}

Assegid Negash ${ }^{1,2^{*}}$, Matloob Ahmed Khan ${ }^{1}$, Girmay Medhin ${ }^{3}$, Dawit Wondimagegn ${ }^{1}$, Clare Pain ${ }^{4}$ and Mesfin Araya ${ }^{1}$

\begin{abstract}
Background: The prevalence of mental distress among university students in low- and middle-income countries (LMICs) is increasing; however, the majority do not receive evidence-based psychological intervention. This calls for the provision of culturally adapted psychological therapy in higher education institutions in LMICs. The aim of this pilot study is to evaluate the feasibility and acceptability of Interpersonal Psychotherapy adapted for Ethiopia (IPT-E) among Wolaita Sodo University students and to assess the preliminary outcomes of IPT-E in reducing symptoms of mental distress and in improving functioning.
\end{abstract}

Methods: We used a quasi-experimental single-group pre-post-test study design. As indicators of feasibility of IPT-E, we used consent, treatment completion and attrition. We used Client Satisfaction Questionnaire and semi-structured interview to measure the acceptability of the intervention, self-reporting IPT-E checklist to assess treatment adherence and World Health Organization Disability Assessment and Self-Reporting Questionnaire-20 tools to assess functional impairment and mental distress, respectively. We used percentage, frequency, mean and standard deviation to summarize the demographic variables, feasibility and acceptability of IPT-E. We analyzed changes from pre- to post-tests of mental distress and functioning results using paired t-test and Wilcoxon signed-rank tests. Independent sample t-test and one way-ANOVA used to assess the difference in mean score of in demographic variables at baseline and eight weeks. The qualitative data was analyzed with the support of open code 4.02.

Results: IPT-E was feasible (consent rate $=100 \%$; completion rate $=92.31 \%$; attrition rate $=7.69 \%$; mean score of the sessions $=8$ and mode of the session $=8)$. The total mean score of treatment satisfaction was $27.83(\mathrm{SD}=4.47)$. After the delivery of IPT-E, symptoms of mental distress were decreased, functioning was improved and therapist adherence to the treatment model was 100\% (i.e. treatment delivered according to the IPT-E guideline).

Conclusion: IPT-E was feasible and acceptable to treat university students with mental distress in low-income country setting. The preliminary results also suggest promising viability of IPT-E in higher education institutions of lowincome country setting for students with symptoms of anxiety and depression.

Keywords: Mental distress, Feasibility, Acceptability, Interpersonal psychotherapy, University students, Ethiopia

\footnotetext{
*Correspondence: assegidn@gmail.com

${ }^{1}$ Department of Psychiatry, College of Health Sciences, School

of Medicine, Addis Ababa University, Addis Ababa, Ethiopia

Full list of author information is available at the end of the article
}

(c) The Author(s) 2021. This article is licensed under a Creative Commons Attribution 4.0 International License, which permits use, sharing, adaptation, distribution and reproduction in any medium or format, as long as you give appropriate credit to the original author(s) and the source, provide a link to the Creative Commons licence, and indicate if changes were made. The images or other third party material in this article are included in the article's Creative Commons licence, unless indicated otherwise in a credit line to the material. If material is not included in the article's Creative Commons licence and your intended use is not permitted by statutory regulation or exceeds the permitted use, you will need to obtain permission directly from the copyright holder. To view a copy of this licence, visit http://creativecommons.org/licenses/by/4.0/. The Creative Commons Public Domain Dedication waiver (http://creativecommons.org/publicdomain/zero/1.0/) applies to the data made available in this article, unless otherwise stated in a credit line to the data. 


\section{Background}

The prevalence of mental distress understood as the symptoms of anxiety and depression is higher among university students as compared with the general population [1] has increased over the past few years [2]. For instance, the prevalence of depression symptoms among university students is $30.6 \%$ worldwide [3], $24.4 \%$ in lowand middle-income countries (LMICs) [4] and the pooled prevalence of anxiety and depression is $37.73 \%$ among Ethiopian university students [5]. Globally reported risk factors of experiencing mental distress among students are: (i) academic pressure and financial constraints, [1, 6]; being away from home for the first time and starting new peer relations [7]; inadequate social support $[8,9]$; (iv) loneliness [10]; (v) substance use [11]; (vi) earlier age of onset of symptoms [12], where most of university students' age range from 17 to 25 years [13]; and (vii) interpersonal conflicts [14].

Increased severity of mental distress along with the lack of access to professional mental healthcare are associated with an adverse effect on students' academic achievement, physical health, emotion, self-esteem, social relationships, cognitive development, and their overall quality of life. Evidence showed that students with mental distress and who did not receive mental healthcare timely experienced low academic performance [15] and suicidal thoughts and attempts [16]. A Previous study reported that college students who experienced depression and sleep disturbance in America had a high burden of comorbid anxiety and poor mental and physical functioning [17]. The burden and functional disabilities of mental distress are more severe in LMICs university students [7], where the accessibility of psychological interventions is limited.

Despite the increasing number of universities in LMICs and a growth in the proportion of students enrolled in these universities, the provision of professional mental health services for students remains underdeveloped, largely because there are insufficiently trained therapists/ counselors [18]. As a result, the majority of the students in LMICs do not receive professional mental health care, even if the students request or require it [19]. Most students in need receive support from informal sources such as friends, family, traditional healers, and religious leaders [20]. In some settings in LMICs the inability of students to receive formal mental health services may be associated with an increase in the severity of mental distress and the development of Common Mental Disorders (CMDs), withdrawal from the university, substance use, self-harm and suicide, low self-esteem, isolation, and poor academic performance [21-24]. In so far as the prevalence and burden of anxiety and depression are rapidly increasing among students, universities are advised to ensure adequate student counseling services to prevent and treat student for distress and mental health symptoms [25]. Early detection of mental distress and feasible psychological interventions are needed in LMICs universities, to combat the negative impacts of mental distress on education performance, social interactions, health, and functional impairments of students [10, 26].

Psychological interventions are effective in treating CMDs (anxiety and depression) in LMICs [27] and are recommended by the World Health Organization intervention guide [28]. When employed they result in fewer relapses and premature treatment termination as compared to pharmacotherapy for students with depression [29]. Of the potential psychological interventions, Interpersonal Psychotherapy (IPT) is effective in resolving symptoms of depression and anxiety and improving interpersonal relationships and has been used in primary health centers in LMICs, including Kenya [30], South Africa [31], Egypt [32], and Ethiopia [33]. IPT is an evidence based brief time-limited manualized therapy, which is used to treat clients who struggle with depression associated with current interpersonal dispute/conflict, role transitions/life changes, grief/loss and social isolation/loneliness [34].

Interpersonal conflict is defined as "a situation in which the patient and at least one significant other person have non-reciprocal expectations about their relationship" [34] informally understood as disagreements, arguments and disputes. During the university stay, students who experience conflict with their friends and family increases their likelihood of developing mental distress $[14,35]$. Interpersonal conflict is chosen as an IPT focus area when worsening symptoms are connected to disagreements and arguments. Role transition is focal area of IPT that is defined as an individual who is unable to adapt to new life changes (both positive and negative) that include moving away from the family, poverty, separation or rejection by a lover, caring for someone who is dying, serious illness and getting marriage [34]. All university students face role transitions and it is chosen as an IPT target when worsening symptoms are linked to significant life changes with challenges to adapt to new circumstances.

Grief is another IPT focal area that occurs when a student loses a significant person by death [36]. It is common to experience grief reactions such as sadness, feelings of discomfort, guilt and anger for most people across the world, but if it fails to resolve within a reasonable time dictated by local cultural expectations, it increases the risk for CMDs and it negatively affects students' academic performance and quality of life [36-38]. Besides, prolonged grief impairs participation in social or enjoyable activities, deprives mood and deny the death of 
the closed person [39]. The last IPT focus area is social isolation, which is associated with the person talks about feeling lonely and separate from others that are caused by problem of maintaining relationships with friends, family, relatives or others [34].

However, the feasibility and acceptability of IPT has not been well studied in LMIC university setting, where most students' mental distress is mainly caused by role transitions, interpersonal conflicts and grief. At the global level, some studies showed the feasibility and acceptability of IPT among adolescents. For example, a quasi-experimental study conducted in Columbia reported that brief IPT was feasible and acceptable in reducing mild to moderate symptoms of depression and improving social functioning among adolescent students [40]. A systematic review and meta-analysis also reported that IPT was an effective therapy to treat adolescents with symptoms depression $[10,41]$. Furthermore, an experimental study conducted among Iranian university students reported that students who received brief group IPT showed a significant reduction in depression symptoms compared to the control group [42]. However, a study conducted in Australia reported that individual IPT is more effective than group IPT for treating depressed adolescents at school setting [43]. Likewise, another evidence showed that the majority (95\%) of the college students prefer individual psychotherapy to group counseling [44].

The high prevalence of mental distress and challenges encountered by university students in LMICs are a call to implement culturally appropriate evidence-based and practical psychological intervention. Although previous studies recommend the need for accessible and acceptable evidence-based mental health interventions for university students with mental distress, to our knowledge, there is no published evidence from studies conducted in Ethiopia on the feasibility and acceptability of IPT for university students with mental distress. The primary aim of this pilot study was to evaluate the feasibility and acceptability of brief individual Interpersonal Psychotherapy adapted for Ethiopia (IPT-E) among Wolaita Sodo University (WSU) students. And the secondary objective was to evaluate outcomes that include the preliminary effectiveness of IPT-E in reducing symptoms of mental distress and improving functioning.

\section{Methods}

\section{Study area and context}

The current study was conducted at WSU, a non-profit public university in Wolaita zone, Wolaita Sodo City which is located $320 \mathrm{~km}$ south of Addis Ababa, the capital of Ethiopia. The University was established in 2007 with intake of 801 students in four faculties and sixteen departments. Currently, the University runs undergraduate and graduate programs in regular, weekend and summer courses in six colleges and five schools with a total student population of 30,000. The University has its own health service facilities and it has four fulltime counselors with four counseling offices that provide free counseling services for students with mental health and psychosocial problems. WSU has a referral teaching hospital (named as Otona) that provides health care services, including psychiatric care for the surrounding community and students. A dedicated clinic within the university compound provides health care services for students and it has a referral system with the hospital for students with severe physical and mental illnesses. In response to the occurrence of coronavirus (COVID-19) pandemic the University has established a Mental Health and Psychosocial Support center to help students with COVID-19 related issues.

\section{Study design}

We used a quasi-experimental single group pre- and post-test design with repeated measures for secondary outcomes. The data were collected from December 2019 to February 2020.

\section{Study participants and their recruitment procedures}

Our source population is undergraduate students in WSU. We posted flyers in target areas, including: the students' dormitories and cafeteria, the main gate of the university, the library, and student's health clinic. In addition, we prepared three banners in collaboration with the WSU student's Dean and counseling offices. These banners were posted in the same strategic areas as the flyers. The flyers and banners were written in Amharic, the official language of Ethiopia which most students speak. The flyers and banners encouraged those students who experienced symptoms of psychological distress to come to student services for IPT-E. The flyers and banners included the names, addresses and contact data of the counselors as well as their time of availability.

The counselors registered students that came to the counseling offices requesting assistance following the distribution of the flyers and erection of the banners, and screened them based on eligible criteria for IPT-E: they were an undergraduate student; scored 8 or more on SRQ-20; they were 18 years or older; willing to attend at least 4 IPT-E sessions and able to speak the Amharic or Wolaitigna or Afan Oromo language. The exclusion criteria were: students with serious physical illnesses; suffering from cognitive impairment; severe mental illness; and already receiving psychiatric medication or psychological treatment or traditional treatment. The counselors asked the students some questions to identify these exclusion 
criteria. Twenty six eligible students were recruited and participated in the IPT-E sessions. See Fig. 1.

IPT has been adapted to the Ethiopian context in collaboration with Toronto Addis Ababa Psychiatry Project and the Biaber Project and named Interpersonal Psychotherapy adapted for Ethiopia (IPT-E) [33]. This culturally adapted talk therapy is a brief manualized evidence supported intervention used to treat clients with CMDs caused by loss, life transitions/role changes, and interpersonal conflicts [33]. Social isolation was not considered as focal area of IPTE, because in a country where everyone lives in a community, the issues of social isolation and IP deficit are rare foci for symptoms. The IPT-E manual has 8 modules, 4 that contains a basic and interactive orientation to mental health in Ethiopia, including mental health service delivery, mental health risks and resilience, the therapy relationship, safety issues, mental health screening, and 4 modules on the IPT-E: beginning phase, middle phase, termination phase, using relevant example cases and includes an evaluation of IPT-E training outcomes. In addition, the manual has Amharic language case-based training videos.

The IPT-E beginning phase includes screening a client for mental distress; how to select cases appropriate for IPT-E; ensuring consent to participate in the treatment; and screening for client safety such as suicide, domestic violence, harming others and substance use. The counselors understand clients' problems, symptoms, functioning, and explanatory model using a Treatment Tracking Form (TTF). They also conduct an interpersonal inventory, and provide tailored psycho-education for the client. Finally, the counselors formulate one or maximum two IPT-E focus area/s (grief, life change or disagreements) for the next middle phase of the intervention.

The middle phase of IPT-E is the heart of the intervention, where general techniques such as role play, psychosocial supports, brainstorming, and communication analysis were practically implemented on the selected IPT-E focus area/s. This occurred in combination with several techniques to address the focus area specifically. In this phase, symptoms and functioning are tracked at each session using the TTF. In the termination phase, the counselor reviews the client's efforts, progress, therapeutic achievements and changes made in the beginning and middle phases. Throughout treatment the counselor has an IPT-E treatment checklist to note the various IPT-E activities used in the counseling process.

The IPT-E was conducted on a weekly basis and lasted for $40-60 \mathrm{~min}$ per session. The number of sessions attended in the IPT-E ranged from 4 to 8 . IPT-E has a screening tool which consists of 6-items used to identify participants with mental distress. Both the screening and treatment were given by four counselors under the close supervision of the principal investigator in their own counseling offices, which were well furnished, ventilated, and attractive. All the counseling offices are situated in the same building as the student's clinic, which promoted a robust referral system and avoided stigma of student clients having separate mental health services. The sessions were not audio-recorded because clients were not comfortable with this. However, the delivery of IPT-E in every session was documented by the counselors using the IPT-E treatment checklist. All counselors had their clients' cell phone numbers to remind them of the time of

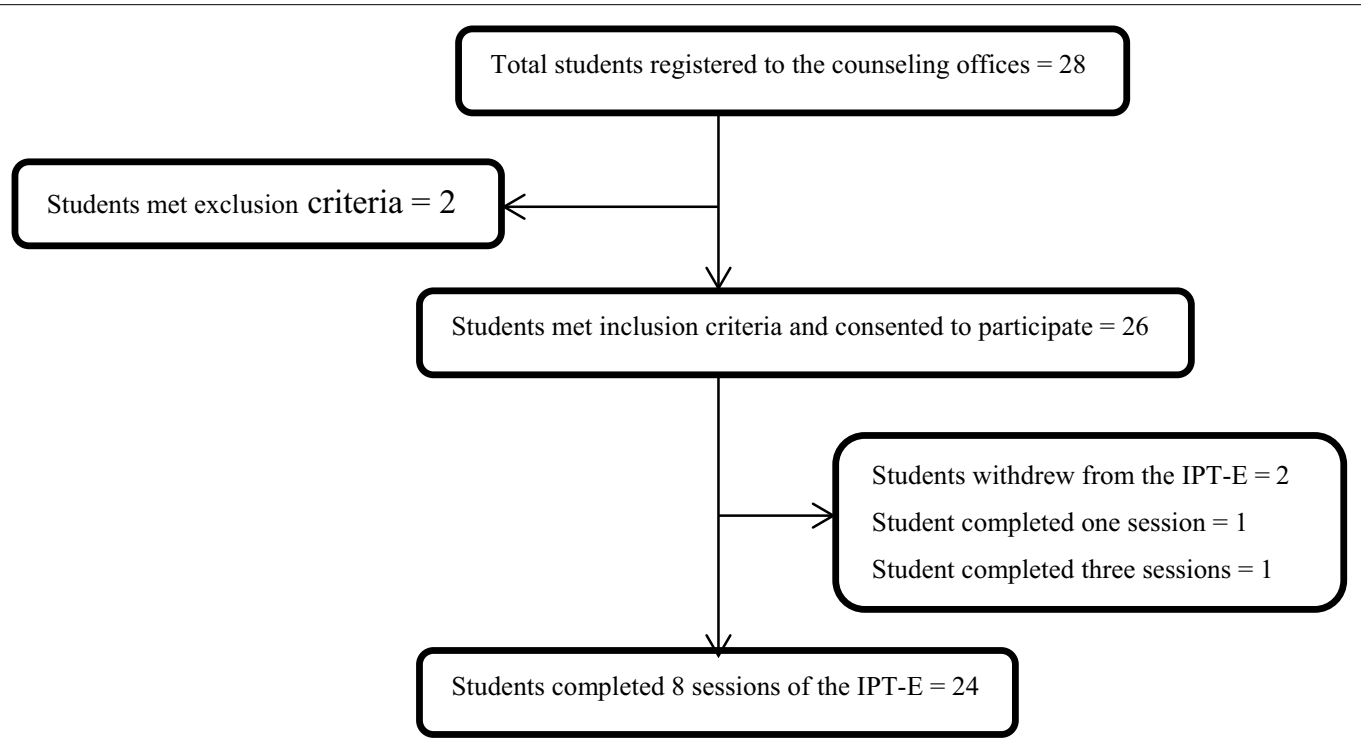

Fig. 1 Flow of study participants 
their appointment. Clients who had to miss a session due to unexpected events agreed in advance to communicate his/her counselor via cell phone and then rebook for the next appropriate day. The first author of the article supervised the counselors' work every week.

\section{IPT-E training for counselors}

The intensive IPT-E training was given for four consecutive days and included practical sessions on the clinical skills required. Initially, five counselors participated in the training, but four completed the training. The two women counselors had a Bachelor degree in Public Health, one male counselor had a Master's degree in Public Health and the other had a Master's degree in Counseling Psychology. Three of them could speak Amharic and Wolaitigna languages fluently and one counselor could speak Afan Oromo and Amharic languages fluently. The training was given by the principal investigator who has a Bachelor's degree in Psychology, a Master's degree in Counseling psychology, had 2 years counseling experience in WSU counseling office and has attended the theoretical and practical training of IPT-E given by the manual adaptors.

To evaluate the outcome of the training, the trainer administered pre- and post-tests prepared from the IPT-E manual and a training satisfaction feedback measuring tool. All counselors showed a significant change in the post-test result compared to the pre-test indicating that the counselors received the necessary knowledge to implement IPT-E in the practical session. The practical sessions also helped them to acquire the clinical skills of implementing IPT-E. Besides this, all the counselors rated the training as excellent and reported that the standard quality of the training was high and fulfilled their expectations. They reported that they received practical knowledge that enabled them to treat students with symptoms of anxiety and depression.

\section{Measures}

Five instruments were used to collect the demographic and outcome data. IPT-E screening tool and TTF were used together to collect data including participants' age, sex, marital status, perceived cause of the problem, treatment received, onset of the problem, concurrent problems, medication, substance use, experience of gender based violence, suicide ideas, plan and past attempts, and thoughts and past attempts of harming others. The second instrument was IPT-E feasibility measuring tool, which was used to evaluate the number of students who attended the intervention session, consent rate, completion rate, attrition rate, the duration of the intervention session attended, and the mean and modal number of sessions completed over 8-weeks.
The third instrument was Client Satisfaction Questionnaire-8 items (CSQ), which was used to measure acceptability of IPT-E. The 8-items were rated on a Likert scale ranging from 1 to 4 that yield a minimum total score of 8 and a maximum total score of 32 [45]. In addition to this, a semi-structured interview was conducted with 10 clients to explore further satisfaction received from the intervention. Redundancy of the clients' response to the open ended questions framed from CSQ indicated the saturation of the data. The qualitative data were audiotaped. The fourth was fidelity to the IPT-E treatment that included intervention adherence and the number of session attended (dose) [46]. This treatment adherence was assessed by the IPT-E treatment self-report checklist, which was coded as "yes" or "no" ("yes" indicates the accomplishment of the expected key tasks within each session and "no" represents a failure to accomplish the expected key activities in each counseling session). The counselors completed the checklist for every session of the IPT-E.

The fifth tool was World Health Organization Disability Assessment (WHODAS-2.0) [47]. This instrument is a self-administered 12-item scale designed to measure functional difficulties caused by mental distress in the past 30 days. It has six functional domains which are: understanding and communicating, getting around, self-care, getting along with people, life activities, and participation in society with a Likert scale ranging from 1 (none) to 5 (extreme/cannot do). Scores are computed either by adding the response of items in each domain separately or by adding all the responses together to get a global score. A higher score indicates greater functional impairment. WHODAS-2.0 has been adapted and validated in Ethiopia for people with severe mental illness [48].

The six instrument was Self-Reporting Questionnaire-20 items (SRQ-20) used to measure the extent of mental distress in the last 30 days. This tool is primarily developed by WHO and recommended to LMICs to screen positive cases of mental distress [49]. It has binary options (yes $=1$ indicating the presence of the symptom, no $=0$ indicating the absence of the symptom). Adding each item gives a maximum total score of $20^{\prime \prime}$ [50]. The SRQ-20 has been validated in Ethiopia with different cutoff points [51, 52]. For the present study, we used a cutoff point 8 or above on SRQ-20 to identify positive cases to mental distress based on a previous validation study [53].

See Additional file 1.

\section{Data analyses}

In the present study, data were collected at baseline and at eight-weeks. The data collected using SRQ-20 and 
WHODAS-2.0 were measured twice, whereas the data measured by CSQ, IPT-E feasibility measuring tool, and interviews of the clients were collected at eight weeks. The quantitative data were analyzed using Statistical Packages for the Social Sciences version 20 after cleaning, checking the missing values, outliers, and after checking normality assumption of the distribution of continuous variables. The demographic variables, feasibility and acceptability of IPT-E and treatment satisfaction were summarized using percentage, frequency, mean, and standard deviation.

The preliminary effectiveness of IPT-E measured by SRQ-20 at pre- and eight weeks were analyzed using paired t-test and the functioning data measured by WHODAS-2.0 at baseline and post-assessment were analyzed by Wilcoxon signed-rank test. Independent samples t-test and one-way ANOVA were used to compare the mean score difference of two and more categorical variables with normally distributed continuous outcomes, respectively. The effect size was interpreted based on $0.01=$ small effect; $0.06=$ moderate effect; and $0.14=$ large effect [54]. Statistical significance was reported whenever $p$-value was less than 0.05 . The audiotaped qualitative data of the acceptability of IPT-E were transcribed verbatim and translated and then analyzed using thematic analysis approach supported with a qualitative software, open code 4.02 [55].

\section{Ethical issues}

All the ethical considerations and the methodological plausibility of the current study were done according to Addis Ababa University College of Health Sciences (AAU-CHS) Institutional Review Board [28] guideline. Ethical clearance was obtained from the IRB of AAUCHS with protocol number of $045 / 17 /$ Psych. The intervention was initiated after receiving written informed consent from all study participants. The participants were informed that they could withdraw from the study at any time if they were not comfortable participating in the study, without prejudice. There was a referral system through the students' clinic to the Otona hospital for those students who met the exclusion criteria of the present study. As a result, two students who were previously diagnosed with severe mental illness and taking psychotropic medications were referred to the Otona hospital for further psychiatric care. Finally, the collected data were kept anonymous and confidential throughout the whole study process by locking the computer using a password known only by the principal investigator. The data documented on the hard copies were kept in locked box of the principal author's house.

\section{Result}

Demographic characteristics of the study participants The proportion of male-female participants was equivalent $(50 \%)$ and $79.2 \%$ were single. Their age ranged from 18 to 23 years with a mean age of 21 years $(\mathrm{SD}=1.49)$. The majority $(75 \%)$ perceived that the causes for their mental distress were disagreement (conflicts with family, friends and dorm mates and life changes (being new to university life, separation or rejection by a lover and loss of support/economic hardship). All participants were not receiving treatment from traditional healers or from other sources throughout the study period and 50\% reported that their distress started before two years prior to this study. All participants reported that they did not have concurrent medical conditions such as HIV, TB, malaria, diabetes and heart disease and substance use. They were not taking any medication during the intervention period; they reported no previous experience of gender-based violence and no past attempts of suicide and harming others. The majority $(62.5 \%)$ had no thoughts of suicide and $95.8 \%$ had no plan to commit suicide. In the past month the majority $(75.0 \%)$ had no thoughts of harming others (Table 1).

\section{Feasibility of IPT-E}

All participants provided written consent to participate in the IPT-E. Of the 26 eligible participants who initially participated in the intervention, 24 completed the full eight-session treatment resulting a completion rate of $92.31 \%$. The remaining two withdrew from the intervention (one participant attended session one and the other attended three-sessions), which yielded in the attrition rate of $7.69 \%$. These two participants were excluded from the data analysis. The mean, median and mode number of the intervention sessions attended were 8 .

\section{Acceptability of IPT-E}

The total mean score of client satisfaction received for IPT-E was 27.83 ( $\mathrm{SD}=4.47$; range $=12-32)$. The majority $(66.7 \%)$ rated the quality of the intervention they received being excellent; they qualitatively expressed their satisfaction as follows:

A 21-year-old female student said:

"Ok, thank you, eh...the care that I received is like P.PCQY HF English as changing a dried tree to a tree with wet leaf. I received my previous identity; I am confident, strong, have a good communication with my friends (my friends are surprised by my improvement) and I am also happy." (Interviewee \#07). 
Table 1 Demographic characteristics of the participants $(n=24)$

\begin{tabular}{|c|c|c|}
\hline Variable & Number & Percent \\
\hline \multicolumn{3}{|l|}{ Marital status } \\
\hline Single & 19 & 79.2 \\
\hline Married & 2 & 8.3 \\
\hline In relationship & 3 & 12.5 \\
\hline \multicolumn{3}{|l|}{ Age } \\
\hline Mean (Standard deviation) & $20.67(1.49)$ & \\
\hline \multicolumn{3}{|l|}{ Perceived cause of mental distress } \\
\hline Grief & 3 & 12.5 \\
\hline Conflict & 9 & 37.5 \\
\hline Life change/role transition & 9 & 37.5 \\
\hline Conflict and life change & 2 & 8.3 \\
\hline Loss and life change & 1 & 4.2 \\
\hline Did not received treatment from traditional healer during the study period & 100 & 100 \\
\hline \multicolumn{3}{|l|}{ Problem has been present continuously for 2 or more years } \\
\hline Yes & 12 & 50 \\
\hline \multicolumn{3}{|l|}{ Had ideas of suicide in the past month } \\
\hline Yes & 9 & 37.5 \\
\hline \multicolumn{3}{|l|}{ Had plan of suicide in the past month } \\
\hline Yes & 1 & 4.2 \\
\hline \multicolumn{3}{|l|}{ Had thoughts of harming others in the past month } \\
\hline Yes & 6 & 25.0 \\
\hline \multicolumn{3}{|l|}{ Is the client fit for IPT-E? } \\
\hline Yes & 24 & 100 \\
\hline
\end{tabular}

Another 20-year-old male student explained that:

"If I am not able to get her (the counselor) care, I would be a daily laborer and below my friends, because my family cannot afford private college fees to teach me. God showed me the counselor because she saved me the whole of my life. I found it very helpful." (Interviewee \#05).

Forty-six percent of the study participants reported that they definitely received the kind of the services they expected and almost all of their needs were met. Despite this, most students qualitatively expressed the treatment they received as it was beyond their expectations that fully addressed their mental health care needs.

A 21-year-old female student said:

"Normally, when I came to this office, it was because of my friend's advice. I was not expecting to get such kind of service; I just came to tell my Paini mi. (translated as internal turmoil) if somebody is ready to listen to me; however, what I was thinking was completely different from what I received. It is beyond my expectation." (Interviewee \#07).
The majority (75.0\%) of the participants reported that they would definitely recommend the intervention received to their friends in need of similar care. Over half (54.20\%) reported that they were very satisfied with the intervention they received. They qualitatively expressed that all of them were satisfied by the treatment given to them and they would recommend for their friends with mental distress in need of similar mental health care.

A 23-year-old male student said:

"If I love him (friend), why not bring him here? Because I'm satisfied with the service I received... (laugh). Our prophet said that one person is said to be not believed in Islam until he loves what he loves for his brother. Because I am satisfied with the therapy; I am happy to bring my friends who have a problem, even anyone on the street suffering from such a problem if it is not adding a burden on the counselor. Normally, I was laughing a false laugh before therapy, however, now I am normally happy even when I did not score a good exam result." (Interviewee \#01).

Another participant stated: 
"Yes, I received important advice that not only helps me but also enables me to even advise someone else; now I can advise another person who has similar feelings of distress. The interviewer asked, you mean you can replace the counselor? Yes, laugh...laugh... I can send other people with a problem by informing them there is a counselor who provides counseling services and I can bring them here." A 20-year-old male interviewee \#04.

Most $(70.80 \%)$ participants reported that the mental health service they received helped them effectively deal with their problem and half $(50 \%)$ of them rated their overall treatment satisfaction as mostly satisfied or very satisfied.

A 23-year-old male student said:

"Extremely, my face speaks; I am very happy today; my previous happiness has returned again; I started to communicate with many people. Previously even I do not know the name of the students in our class; I asked my friend who was this student in our class? You know I entered to the class before anyone and sat at the back corner and I left the class at the end when all students went out. But now, I play and communicate with the students; we go together up-to the dormitory. I have a good relationship with my dorm mates; there is a student who disturbs me in the dormitory; I tolerate him very well; if I were in my previous mental state, I would have conflict with him." (Interviewee \#01).

Most (62.5\%) participants reported that they would definitely return to the counseling office if they need care again.

22-year-old male student explained:

"I hope I would not have to face the problem, but if it occurs again, I will come back." (Interviewee \#08)

There was no statistically significant difference in any of the demographic variables in the treatment satisfaction.

\section{Fidelity}

The majority of the participants attended 8 IPT-E sessions. Each session lasted 40 to $60 \mathrm{~min}$ as is recommended by the IPT-E guidelines. In addition to the provision of training for the counselors and regular supervision of the delivery of IPT-E counseling service, the accomplishment of the key activities to be done in each session were immediately evaluated. All counselors ticked "yes" for all activities, indicating that the necessary tasks were done in each of the IPT-E sessions.

See Additional file 2.

\section{Outcome evaluation}

The IPT-E showed preliminary effectiveness in decreasing symptoms of mental distress and improving functioning among students. There was a statistically significant decrease $(p$-value $=0.001)$ in mean score symptoms of mental distress from baseline $(M=14.13$, $\mathrm{SD}=3.70)$ to eight weeks post assessment $(M=3.21$, $\mathrm{SD}=3.12$ ) with effect size of 0.89 (large effect). At the post-assessment, four participants (16.6\%) scored above the cut-off 8 on SRQ-20 (2 participants scored 10 points and another 2 participants scored 14), even if they showed symptoms reduction in mental distress from the baseline.

The data collected through Treatment Tracking Form (TTF) showed an improvement of mental distress in each session. Likewise, there was reduction in the frequency of mental distress symptoms from pre-to-post assessment in the past two months. During the pre-test a large proportion of the participants reported that they experienced symptoms such as being sad, miserable or hopeless (46\%); had little pleasure in doing things (54\%); felt anxious (67\%); and experienced a lack of energy on several days in the past one month (50\%). Of all participants, $29 \%$ felt restlessness and $38 \%$ had trouble concentrating on conversations or reading nearly every-day in the past month. Of the total participants, 33\% felt bad about themselves and unable to control worrying several days or nearly every-day in the past one month and $42 \%$ had trouble sleeping nearly every-day in the last month. Furthermore, $46 \%$ of the participants felt afraid that something awful might happen without a reason and 50\% experienced more than 5 physical symptoms several days in the past month.

After the two months IPT-E intervention, the majority (75\%) of the participants had not felt symptoms such as being sad, miserable or hopeless and $71 \%$ had pleasure in doing things. The majority (75\%) reported that they had no symptoms of anxiety and 79\% recovered their energy after the intervention they received. Almost all (91.70\%) of the participants felt symptoms such as restlessness and feeling bad about themselves had remitted. They no longer had difficulty concentrating on conversations or reading after the intervention they received. Most (79\%) participants no longer experienced problems controlling they worrying and $88 \%$ were sleeping well. Finally, the majority (75\%) lost their dread of something awful happening without reason and $83 \%$ no longer had 5 or more physical symptoms. For further information see Table 2.

The overall mean score of WHODAS-2 was significantly improved $(p$-value $=0.001)$ from baseline $(M=34.33, S D=10.70)$ to post assessment $(M=22.71$, $\mathrm{SD}=8.34$ ) with effect size of 0.43 , (large effect). The mean scores of WHODAS sub-scales were significantly 
Table 2 Pre and post-tests percentage of metal distress symptoms

\begin{tabular}{|c|c|c|c|c|c|c|c|c|c|}
\hline \multirow[t]{2}{*}{ Questions } & \multicolumn{5}{|l|}{ Pre-test } & \multicolumn{4}{|c|}{ Post-test } \\
\hline & Not sure (\%) & $\begin{array}{l}\text { Several } \\
\text { days } \\
(\%)\end{array}$ & $\begin{array}{l}\text { Over half } \\
\text { the days } \\
\text { (\%) }\end{array}$ & $\begin{array}{l}\text { Nearly } \\
\text { every day } \\
\text { (\%) }\end{array}$ & Never (\%) & $\begin{array}{l}\text { Several } \\
\text { days } \\
\text { (\%) }\end{array}$ & $\begin{array}{l}\text { Over half } \\
\text { the days } \\
\text { (\%) }\end{array}$ & $\begin{array}{l}\text { Nearly } \\
\text { every day } \\
\text { (\%) }\end{array}$ & Never (\%) \\
\hline $\begin{array}{l}\text { Felt sad, miserable, down or hope- } \\
\text { less? }\end{array}$ & & 45.8 & 12.5 & 37.5 & 4.2 & 16.7 & 4.2 & 4.2 & 75 \\
\hline $\begin{array}{l}\text { Felt little pleasure or interest in } \\
\text { doing things? }\end{array}$ & 4.2 & 54.2 & 8.3 & 25 & 8.3 & 16.7 & 4.2 & 8.3 & 70.8 \\
\hline Felt nervous/anxious? & & 66.7 & 25 & & 8.3 & 12.5 & 8.3 & 4.2 & 75 \\
\hline $\begin{array}{l}\text { Not enough energy, that every- } \\
\text { thing is an effort? }\end{array}$ & 4.2 & 50 & 20.8 & & 4.2 & 8.3 & 8.3 & 4.2 & 79.2 \\
\hline Felt so restless it is hard to sit still? & 8.3 & 25 & 25 & 29.2 & 12.5 & 4.2 & 4.2 & & 91.7 \\
\hline $\begin{array}{l}\text { Had trouble to concentrating on } \\
\text { conversations/reading? }\end{array}$ & 4.2 & 20.8 & 20.8 & 37.5 & 16.7 & 8.3 & 4.2 & & 87.5 \\
\hline $\begin{array}{l}\text { Felt really bad about yourself, that } \\
\text { you are a failure or that you have } \\
\text { let your family down? }\end{array}$ & 12.5 & 33.3 & 12.5 & 20.8 & 20.8 & 4.2 & 4.2 & & 91.7 \\
\hline $\begin{array}{l}\text { Felt you could not stop or control } \\
\text { worrying? }\end{array}$ & 8.3 & 33.3 & & 33.3 & 25 & 16.7 & 4.2 & & 79.2 \\
\hline Had trouble sleeping? & 8.3 & 12.5 & 20.8 & 41.7 & 16.7 & 4.2 & 4.2 & & 87.5 \\
\hline $\begin{array}{l}\text { Felt afraid as if something awful } \\
\text { might happen without a reason? }\end{array}$ & 16.7 & 45.8 & & 20.8 & 16.7 & 20.8 & 4.2 & & 75 \\
\hline $\begin{array}{l}\text { How many days have you had } \\
\text { more than } 5 \text { physical symptoms } \\
\text { (e.g. aches and pains, palpita- } \\
\text { tions, burning/numbness/crawl- } \\
\text { ing sensations)? }\end{array}$ & 4.2 & 50 & 4.2 & 25 & 16.7 & 12.5 & 4.2 & & 83.3 \\
\hline
\end{tabular}

improved from baseline to eight weeks assessment. For detail information, see Table 3 .

A total number of days suffering from mental distress among the participants were reduced following the intervention.

Change in mental distress following the intervention stratified by selected variables.

Baseline mean score of SRQ-20 was significantly influenced by gender, duration of depressive symptoms and reporting thoughts of harming others in the past month. However, at the post-test, mean score of SRQ20 was not significantly affected by any of the pre-specified characteristics of the study participants. There was no statistically significant difference in the mean score of SRQ-20 by marital status and perceived causes of mental distress both at baseline and post-assessment (Table 4).

Table 3 Functioning at baseline and post-test

\begin{tabular}{|c|c|c|c|c|c|c|c|}
\hline \multirow[t]{2}{*}{ Measure } & \multicolumn{2}{|c|}{ Baseline $(n=24)$} & \multicolumn{2}{|c|}{ 8-weeks ( $n=24)$} & \multirow[t]{2}{*}{ Effect size } & \multirow[t]{2}{*}{ Z } & \multirow[t]{2}{*}{$P$} \\
\hline & $M$ & SD & $M$ & SD & & & \\
\hline \multicolumn{8}{|l|}{ WHODAS sub-scales } \\
\hline Understanding communicating & 5.83 & 2.04 & 4.00 & 2.17 & 0.32 & -3.28 & 0.001 \\
\hline Getting around & 5.63 & 2.14 & 3.88 & 1.94 & 0.33 & -3.34 & 0.001 \\
\hline Self-care & 3.92 & 2.12 & 2.83 & 1.24 & 0.20 & -2.37 & 0.02 \\
\hline Getting along with people & 5.67 & 2.71 & 3.96 & 2.03 & 0.21 & -2.45 & 0.01 \\
\hline Life activities & 6.42 & 2.24 & 3.38 & 1.35 & 0.41 & -3.96 & 0.001 \\
\hline Participation in society & 6.88 & 1.75 & 4.67 & 1.93 & 0.39 & -3.80 & 0.001 \\
\hline Total WHODAS-2 score & 34.33 & 10.70 & 22.71 & 8.34 & 0.43 & -4.18 & 0.001 \\
\hline
\end{tabular}

$\mathrm{M}=$ Mean; $\mathrm{SD}=$ Standard deviation; $\mathrm{Z}=\mathrm{Z}$-value; $P=P$-value 
Table 4 Mean score and standard deviation of selected variables at baseline and post-test

\begin{tabular}{|c|c|c|c|c|c|c|c|c|}
\hline \multirow[t]{2}{*}{ Variable } & \multicolumn{4}{|c|}{ SRQ-20 score at baseline } & \multicolumn{4}{|c|}{ SRQ-20 score at 8-weeks } \\
\hline & M & SD & $\mathrm{T} / \mathrm{F}$ & $P$ & $M$ & SD & $T / F$ & $P$ \\
\hline Sex & & & & & & & 2.02 & 0.06 \\
\hline Male & 12.58 & 3.29 & 2.21 & 0.04 & 2.00 & 3.19 & & \\
\hline Female & 15.67 & 3.55 & & & 4.42 & 2.64 & & \\
\hline $\begin{array}{l}\text { Has the problem been present continuously for } 2 \text { or } \\
\text { more years? }\end{array}$ & & & & & & & 0.58 & 0.57 \\
\hline No & 12.25 & 3.70 & -2.84 & 0.01 & 3.58 & 3.26 & & \\
\hline Yes & 16.00 & 2.70 & & & 2.83 & 3.07 & & \\
\hline Ideas of suicide & & & & & & & 1.07 & 0.3 \\
\hline No & 12.87 & 3.50 & -2.36 & 0.03 & 3.73 & 3.45 & & \\
\hline Yes & 16.22 & 3.15 & & & 2.33 & 2.40 & & \\
\hline Thoughts of harming others in the past month & & & & & & & -1.2 & 0.25 \\
\hline No & 13.28 & 3.51 & -2.08 & 0.05 & 2.78 & 2.96 & & \\
\hline Yes & 16.67 & 3.27 & & & 4.50 & 3.51 & & \\
\hline \multicolumn{9}{|l|}{ Marital Status } \\
\hline Single & 14.63 & 3.85 & 0.86 & 0.44 & 3.26 & 3.41 & 0.38 & 0.69 \\
\hline Married & 12.50 & 0.71 & & & 1.50 & 0.71 & & \\
\hline In relationship & 12.00 & 3.46 & & & 4.00 & 1.73 & & \\
\hline \multicolumn{9}{|l|}{ Perceived cause } \\
\hline Loss & 14.33 & 4.73 & 0.26 & 0.90 & 3.26 & 5.51 & 1.57 & 0.22 \\
\hline Disagreement & 14.88 & 3.89 & & & 4.33 & 2.00 & & \\
\hline Life change & 13.11 & 4.08 & & & 2.22 & 3.07 & & \\
\hline Disagreement and life change & 15.00 & 0.00 & & & 0.00 & 0.00 & & \\
\hline Loss and life change & 14.00 & 0.00 & & & 7.00 & 0.00 & & \\
\hline
\end{tabular}

$\mathrm{M}=$ Mean; $\mathrm{SD}=$ Standard Deviation; $\mathrm{T}=\mathrm{T}$-value for $\mathrm{t}$-test $; \mathrm{F}=\mathrm{F}$-value for ANOVA

\section{Discussion}

Findings of the current study indicated that IPT-E is feasible and acceptable for university students with mental distress in Ethiopia. All eligible students consented to participate in the intervention and only two of them did not complete the 8-session individual IPT-E intervention. Overall, participants were highly satisfied with the care they received. IPT-E provided a promising preliminary result in Ethiopian University in decreasing symptoms of mental distress and improving functioning of university students.

Most of the study participants completed the 8 weekly sessions, which is comparable with the previous feasibility studies where the majority of depressed adolescents completed brief individual interpersonal counseling [40, 56]. The possible justifications for the feasibility of the IPT-E were: the counselors had received intensive training supported by clinical practice which helped them to engage the students; close supervision by the lead author of this paper; use of a fidelity checklist and the preparedness of the clients to give their counselors advanced notice of their absence. Besides this, our study was conducted in a building where a students' general medical clinic is located so students are not seen to be attending a mental health clinic. This potentially minimized stigma and increased the likelihood of attending the IPT-E sessions regularly [40]. In addition, the rapport building emphasis of IPT-E also played a role for most participants who attended all 8 sessions [57]. However, two participants withdrew from the IPT-E intervention, because one participant was transferred to a university near to his family and the other was not willing to continue the intervention because he was too busy with school work.

Study participants reported that they were highly satisfied with the intervention they received, indicating that IPT-E was acceptable. A previous study reported that adolescents who received brief IPT were highly satisfied with the care they received [40]. Similarly, in another study adolescents who received 8 sessions of IPT treatment were mostly satisfied/very satisfied with the care they received [58]. As well, the small attrition rate in the present study directly indicates the acceptability of the intervention being provided to the students. The present study has also shown very good treatment adherence what almost all participants completed all 8 treatment session, which is comparable to a prior study in which 
the treatment adherence of interpersonal counseling by the counselors was reported as good [56]. Along with the educational status of the counselors, the didactic training supported by clinical practice and ongoing clinical supervision enabled the counselors to effectively deliver the IPT-E intervention which is also likely to be linked to the participants' satisfaction with the rendered counseling service.

The implementation of IPT-E indicated promising results demonstrating a significant decrease of the symptoms of mental distress and by improving functioning of the university students in the study. This finding is consistent with previous studies where most adolescents showed significant improvement in symptoms of depression and social functioning after receiving IPT intervention [40, 43, 56]. Another studies also reported that adolescents who received IPT showed a reduction of depression symptoms as compared to a control group $[59,60]$. Similarly, a study in a higher education institution reported that students who received IPT had significantly reduced symptoms of depression compared to a control group [42]. Other reasons associated with the preliminary effectiveness of IPT-E to improve mental distress and functioning are the didactic training and ongoing clinical supervision of the counselors which enabled them to provide IPT-E intervention. As well, ongoing monitoring of the students' mental distress symptoms and functioning; and the fact that good cognitive capacities [61] and high educational level [62] are associated in the literature with a good response to mental health interventions.

The first onset of most mental health disorders occurs in the age range of 15-25 years [12] and most undergraduate university students are within this age category. As evidence shows, the first-onset of mental health problem can be treated better than the recurrent mental health problem, which might explain why the preliminary effectiveness of IPT-E among the students is high [25]. Other reports note that mild to moderate mental distress among adolescents responds more easily to IPT as compared to severe mental distress $[40,56]$. Culturally adapted IPT-E and the high completion of treatment rates of the participants contributed to the improvement of the above mentioned clinical outcomes. This coincide with the results of previous studies where culture tailored mental health interventions enhanced the effectiveness of psychological therapy $[40,56,60]$ and the greater number of counseling session attendance predicted the success of mental health intervention [63]. The ideal number of a brief counseling session for anxiety and depression ranges from 6 to 8 sessions [64], which fits with our finding where the mean attendance of IPT-E session was 8 . Furthermore, we had taught the counselors during the training and clinical supervision to deliver the counseling service by establishing a good therapeutic alliance and rapport that enhanced the preliminary success of IPT-E in remitting symptoms of mental distress and disability [65].

Limitations: The present study had some limitations: first, our study did not include a comparison group which reduces our confidence in the effectiveness of IPT-E to decrease mental distress and improve functioning. However, the short 8 week time difference between the preand post-test in the present study may have addressed the reduction of symptoms by time alone. Second, the small sample size in the present study may limit the generalizability of the findings, so that the interpretation of the clinical outcomes should be undertaken with caution. Finally, in the present study, there were no followup sessions. We assessed the counselors' adherence to the IPT-E manual, but future studies should measure the clinical competency of counselors. A randomized controlled trial of IPT-E and longer follow-up period would secure the evidence base of IPT-Es to further scale-up the service in similar settings.

Despite the drawbacks, the present study has some strengths, including knowledge and skills transferred to the university health workers on how to effectively treat students with mental distress using the IPT-E guidelines. The other strength was that the close clinical supervision of the counselors' and their adherence to the treatment model increased their knowledge and skills to deliver IPT-E, and extended the capacity of the students' clinic to address to distress of student. We used locally adapted instruments to screen participants with mental distress and to measure disability. Lastly, we had balanced number of male and female counselors to comfort the need for study participants in a counseling session; we think this paved the way to equalize the sex ratio of participants in the present study.

\section{Conclusion}

The present findings indicate that IPT-E is a feasible and acceptable intervention for the treatment of students with mental distress in low-income country settings. IPT-E also showed promising preliminary effectiveness in reducing symptoms of mental distress and improving functioning of University students. The present study findings provide viable information for mental health service providers in higher education institutions to use and scale-up the manualized IPT-E intervention designed to treat people with CMDs. Therefore, scaling-up of this intervention to the national level and implementing it in higher education institutions in Ethiopia would potentially address the high prevalence and burden of mental distress and 
reduce the mental health treatment gap among university students [19], although stronger evidence for IPT-E needs to come from randomized controlled trials.

\begin{abstract}
Abbreviations
LMICs: Low- and Middle- Income Countries; WSU: Wolaita Sodo University; IPTE: Interpersonal Psychotherapy adapted for Ethiopia; CMDs: Common Mental Disorders; COVID-19: Coronavirus; CSQ: Client Satisfaction Questionnaire; WHODAS-2.0: World Health Organization Disability Assessment; SRQ: SelfReporting Questionnaire; ANOVA: Analysis of Variance; SD: Standard Deviation; M: Mean; IPT: Interpersonal Psychotherapy; TTF: Treatment Tracking Form; HIV: Human Immunodeficiency Virus; TB: Tuberculosis; AAU-CHS: Addis Ababa University College of Health Sciences; IRB: Institutional Review Board.
\end{abstract}

\section{Supplementary Information}

The online version contains supplementary material available at https://doi. org/10.1186/s40359-021-00570-1.

Additional file 1. Instruments used for data collection.

Additional file 2. Treatment adherence and dose.

\section{Acknowledgements}

We would like to acknowledge Addis Ababa University and Wolaita Sodo University for funding and material support. We want to thank research participants and counselors for their active participation and time. Finally, we also want to thank all individuals who participated in the adaptation of IPT-E.

\section{Authors' contributions}

AN led to conceiving the study, data collection, developed study design, data analysis, interpretation of the findings, drafted manuscript, and revised the manuscript for submission in consultation with co-authors. MAK contributed to data analysis, commenting on all drafts of the manuscripts, interpretation of the findings, feedback and editing the manuscript. GM contributed to data analysis, commenting on all drafts of the manuscripts, interpretation of the findings, feedback and editing the manuscript. DW was involved in data analysis, commenting on all drafts of the manuscripts, interpretation of the findings, feedback and editing the manuscript. CP contributed to data analysis, commenting on all drafts of the manuscripts, interpretation of the findings, feedback and editing the manuscript. MA led to conceiving the study, data analysis, commenting on all drafts of the manuscripts, interpretation of the findings, feedback and editing the manuscript. All authors read and approved the final manuscript.

\section{Funding}

This study is funded by Addis Ababa University and Wolaita Sodo University. These funders had no role in the study design; data collection, analysis and interpretation of data; in writing the manuscript; and in the decision to submit the paper for publication.

\section{Availability of data and materials}

The datasets used and/or analyzed during the present study are available from the corresponding author on reasonable request.

\section{Declarations}

Ethics Approval and Consent to Participate

Ethical clearance approval obtained from the Institutional Review Board of Addis Ababa University College of Health Sciences. The intervention was initiated after receiving written informed consent from all study participants. The collected data were kept anonymous and confidential throughout the whole study process by locking the computer using a secret password. The data documented on the hard copies were kept in locked box of the principal author's house. Protocol number: 045/17/Psych.
Consent for publication

Not applicable.

\section{Competing interests}

The authors declare that they have no competing interests.

\section{Author details}

${ }^{1}$ Department of Psychiatry, College of Health Sciences, School of Medicine, Addis Ababa University, Addis Ababa, Ethiopia. ${ }^{2}$ Department of Psychology, College of Education and Behavioral Sciences, Wolaita Sodo University, Wolaita Sodo, Ethiopia. ${ }^{3}$ Aklilu Lemma Institute of Pathobiology, Addis Ababa University, Addis Ababa, Ethiopia. ${ }^{4}$ Department of Psychiatry, University of Toronto, Toronto, Canada.

Received: 16 February 2021 Accepted: 19 April 2021

Published online: 27 April 2021

References

1. Stallman HM. Psychological distress in university students: a comparison with general population data. Aust Psychol. 2010;45(4):249-57.

2. Storrie K, Ahern K, Tuckett A. A systematic review: students with mental health problems - a growing problem. Int J Nurs Pract. 2010;16(1):1-6.

3. Ibrahim AK, Kelly SJ, Adams CE, Glazebrook C. A systematic review of studies of depression prevalence in university students. J Psychiatr Res. 2013;47(3):391-400.

4. Akhtar P, Ma L, Waqas A, Naveed S, Li Y, Rahman A, Wang Y. Prevalence of depression among university students in low and middle income countries (LMICs): a systematic review and meta-analysis. J Affect Disord. 2020;274:911-9.

5. Mekuriaw B, Zegeye A, Molla A, Hussen R, Yimer S, Belayneh Z. Prevalence of common mental disorder and its association with Khat chewing among Ethiopian college students: a systematic review and meta-analysis. Psychiatry J. 2020;2020:1-8.

6. Aldiabat KM, Matani NA, Navenec CL. Mental health among undergraduate university students: a background paper for administrators, educators and healthcare providers. Univ J Public Health. 2014;2(8):209-14.

7. Evans-Lacko S, Thornicroft G. WHO World Mental Health Surveys International College Student initiative: implementation issues in low-and middle-income countries. Int J Methods Psychiatr Res. 2019;28(2):e1756.

8. Reta Y, Samuel T, Mekonnen M. Mental distress and associated factors among undergraduate engineering students of Hawassa University. Ethiopia Journal of multidisciplinary healthcare. 2020;13:99.

9. Kebede MA, Anbessie B, Ayano G. Prevalence and predictors of depression and anxiety among medical students in Addis Ababa, Ethiopia. Int J Mental Health Syst. 2019;13(1):30.

10. Duffy A, Saunders KE, Malhi GS, Patten S, Cipriani A, McNevin SH, MacDonald E, Geddes J. Mental health care for university students: a way forward? Lancet Psychiatry. 2019;6(11):885-7.

11. Field T, Diego M, Pelaez M, Deeds O, Delgado J. Depression and related problems in university students. Coll Stud J. 2012;46(1):193-203.

12. Mackean G. Mental health and well-being in post-secondary education settings. In: CACUSS preconference workshop on mental health. 2011 June.

13. Callender J, Fagin J, Jenkins G, Lester J, Smith E. Mental health of students in higher education. London: Royal College of Psychiatrists; 2011.

14. Tesfahunegn TB, Gebremariam EH. Mental distress and associated factors among Aksum University students, Ethiopia: a cross-sectional study. BMC Psychiatry. 2019;19(1):71.

15. Bruffaerts R, Mortier P, Kiekens G, Auerbach RP, Cuijpers P, Demyttenaere K, Green JG, Nock MK, Kessler RC. Mental health problems in college freshmen: prevalence and academic functioning. J Affect Disord. 2018;1(225):97-103.

16. Mortier P, Auerbach RP, Alonso J, Bantjes J, Benjet C, Cuijpers P, Ebert DD, Green JG, Hasking P, Nock MK, O'Neill S. Suicidal thoughts and behaviors among first-year college students: results from the WMH-ICS project. J Am Acad Child Adolesc Psychiatry. 2018;57(4):263-73.

17. Nyer M, Farabaugh A, Fehling K, Soskin D, Holt D, Papakostas GI, Pedrelli P, Fava M, Pisoni A, Vitolo O, Mischoulon D. Relationship 
between sleep disturbance and depression, anxiety, and functioning in college students. Depress Anxiety. 2013;30(9):873-80.

18. Hakim JG, Chidzonga MM, Borok MZ, Nathoo KJ, Matenga J, Havranek E, Cowan F, Abas M, Aagaard E, Connors S, Nkomani S. Medical education partnership initiative (MEPI) in Zimbabwe: outcomes and challenges. Global Health: Sci Pract. 2018;6(1):82-92.

19. Negash A, Khan MA, Medhin G, Wondimagegn D, Araya M. Mental distress, perceived need, and barriers to receive professional mental health care among university students in Ethiopia. BMC Psychiatry. 2020;20:1-15.

20. Gebreegziabher Y, Girma E, Tesfaye M. Help-seeking behavior of Jimma university students with common mental disorders: a cross-sectional study. PLOS ONE. 2019;14(2):e0212657.

21. McGorry PD, Purcell R, Goldstone S, Amminger GP. Age of onset and timing of treatment for mental and substance use disorders: implications for preventive intervention strategies and models of care. Curr Opin Psychiatry. 2011;24(4):301-6.

22. Hawton K, Saunders KE, O'Connor RC. Self-harm and suicide in adolescents. The Lancet. 2012;379(9834):2373-82.

23. Huang J, Nigatu YT, Smail-Crevier R, Zhang X, Wang J. Interventions for common mental health problems among university and college students: a systematic review and meta-analysis of randomized controlled trials. J Psychiatr Res. 2018;107:1-10.

24. Sivertsen B, Hysing M, Knapstad M, Harvey AG, Reneflot A, Lønning $\mathrm{KJ}, \mathrm{O}^{\prime}$ Connor RC. Suicide attempts and non-suicidal self-harm among university students: prevalence study. BJPsych open. 2019;5(2):E26.

25. Cuijpers P, Cristea IA, Ebert DD, Koot HM, Auerbach RP, Bruffaerts R, Kessler RC. Psychological treatment of depression in college students: a metaanalysis. Depress Anxiety. 2016;33(5):400-14.

26. Reavley N, Jorm AF. Prevention and early intervention to improve mental health in higher education students: a review. Early Interv Psychiatry. 2010;4(2):132-42.

27. Van Ginneken N, Tharyan P, Lewin S, Rao GN, Meera SM, Pian J, Chandrashekar S, Patel V. Non-specialist health worker interventions for the care of mental, neurological and substance-abuse disorders in low-and middle-income countries. Cochrane Database Syst Rev. 2013;11(11):CD009149.

28. Dua T, Barbui C, Clark N, Fleischmann A, Poznyak V, van Ommeren M, Yasamy MT, Ayuso-Mateos JL, Birbeck GL, Drummond C, Freeman M. Evidence-based guidelines for mental, neurological, and substance use disorders in low-and middle-income countries: summary of WHO recommendations. PLoS Med. 2011:8(11):e1001122.

29. Hunsley J, Elliott K, Therrien Z. The efficacy and effectiveness of psychological treatments for mood, anxiety, and related disorders. Can Psychol. 2014;55(3):161.

30. Meffert SM, Neylan TC, McCulloch CE, Blum K, Cohen CR, Bukusi EA, Verdeli H, Markowitz JC, Kahn JG, Bukusi D, Thirumurthy H. Interpersonal psychotherapy delivered by nonspecialists for depression and posttraumatic stress disorder among Kenyan HIV-positive women affected by gender-based violence: randomized controlled trial. PLoS Med. 2021;18(1):e1003468.

31. Petersen I, Bhana A, Baillie K, Consortium MRP. The feasibility of adapted group-based interpersonal therapy (IPT) for the treatment of depression by community health workers within the context of task shifting in South Africa. Community Ment Health J. 2012;48(3):336-41.

32. Meffert SM, Abdo AO, Alla OA, Elmakki YO, Omer AA, Yousif S, Metzler TJ, Marmar CR. A pilot randomized controlled trial of interpersonal psychotherapy for Sudanese refugees in Cairo, Egypt. Psychol Trauma: Theory Res Pract Policy. 2014;6(3):240.

33. Ravitz P, Wondimagegn D, Pain C, Araya M, Alem A, Baheretibeb Y, Hanlon C, Fekadu A, Park J, Fefergrad M, Leszcz M. Psychotherapy knowledge translation and interpersonal psychotherapy: using besteducation practices to transform mental health care in Canada and Ethiopia. Am J Psychother. 2014;68(4):463-88.

34. World Health Organization. Group interpersonal therapy (IPT) for depression. Geneva: World Health Organization; 2016.

35. Hersi L, Tesfay K, Gesesew H, Krahl W, Ereg D, Tesfaye M. Mental distress and associated factors among undergraduate students at the University of Hargeisa, Somaliland: a cross-sectional study. Int J Mental Health Syst. 2017;11(1):1-8.
36. Tan J, Andriessen K. The experiences of grief and personal growth in university students: a qualitative study. Int J Environ Res Public Health. 2021;18(4):1899.

37. Roberts KE. Grief and bereavement among college students. 2016.

38. Cupit IN, Servaty-Seib HL, Tedrick Parikh S, Walker AC, Martin R. College and the grieving student: a mixed-methods analysis. Death Stud. 2016;40(8):494-506.

39. World Health Organization. ICD-11 beta draft (joint linearization for mortality and morbidity statistics). World Health Organization. Retrieved August. 2016;26:2016.

40. Mufson L, Yanes-Lukin P, Anderson G. A pilot study of brief IPT-A delivered in primary care. Gen Hosp Psychiatry. 2015;37(5):481-4.

41. Mychailyszyn MP, Elson DM. Working through the blues: a meta-analysis on interpersonal psychotherapy for depressed adolescents (IPT-A). Child Youth Serv Rev. 2018;87:123-9.

42. Nezafat Ferizi J, Mashhadi A, Amin Yazdi SA, Noferesti F. The effectiveness of short-term group interpersonal psychotherapy to symptoms of depression, emotional expressiveness, social skills and quality of life in depressed university students. J Fundam Mental Health. 2015;17(6):318-24.

43. O'Shea G, Spence SH, Donovan CL. Group versus individual interpersonal psychotherapy for depressed adolescents. Behav Cogn Psychother. 2015;43(1):1.

44. Bilican Fl. Help-seeking attitudes and behaviors regarding mental health among Turkish college students. Int J Ment Health. 2013;42(2-3):43-59.

45. Larsen DL, Attkisson CC, Hargreaves WA, Nguyen TD. Assessment of client/patient satisfaction: development of a general scale. Eval Program Plann. 1979;2(3):197-207.

46. Proctor E, Silmere H, Raghavan R, Hovmand P, Aarons G, Bunger A, Griffey $R$, Hensley M. Outcomes for implementation research: conceptual distinctions, measurement challenges, and research agenda. Adm Policy Mental Health Mental Health Serv Res. 2011;38(2):65-76.

47. Üstün TB, Chatterji S, Kostanjsek N, Rehm J, Kennedy C, Epping-Jordan J, Saxena S, Korff MV, Pull C. Developing the World Health Organization disability assessment schedule 2.0. Bull World Health Organ. 2010;88:815-23.

48. Habtamu K, Alem A, Medhin G, Fekadu A, Dewey M, Prince M, Hanlon C. Validation of the World Health Organization disability assessment schedule in people with severe mental disorders in rural Ethiopia. Health Qual Life Outcomes. 2017;15(1):1-1.

49. van der Westhuizen C, Wyatt G, Williams JK, Stein DJ, Sorsdahl K. Validation of the self reporting questionnaire 20-item (SRQ-20) for use in a low-and middle-income country emergency centre setting. Int I Mental Health Addict. 2016;14(1):37-48.

50. Scholte WF, Verduin F, Kamperman AM, Rutayisire T, Zwinderman AH, Stronks K. The effect on mental health of a large scale psychosocial intervention for survivors of mass violence: a quasi-experimental study in Rwanda. PLoS ONE. 2011;6(8):e21819.

51. Hanlon C, Medhin G, Alem A, Araya M, Abdulahi A, Hughes M, Tesfaye $\mathrm{M}$, Wondimagegn $\mathrm{D}$, Patel $\mathrm{V}$, Prince M. Detecting perinatal common mental disorders in Ethiopia: validation of the self-reporting questionnaire and Edinburgh Postnatal Depression Scale. J Affect Disord. 2008;108(3):251-62.

52. Kortmann F, Ten Horn S. Comprehension and motivation in responses to a psychiatric screening instrument validity of the $S R Q$ in ethiopia. $\mathrm{Br} J$ Psychiatry. 1988;153(1):95-101.

53. Youngmann R, Zilber N, Workneh F, Giel R. Adapting the SRQ for Ethiopian populations: a culturally-sensitive psychiatric screening instrument. Transcult Psychiatry. 2008;45(4):566-89.

54. Cohen J. Statistical Power Analysis for the Behavioral Sciences-Second Edition. 12 Lawrence Erlbaum Associates Inc., Hillsdale, New Jersey. 1988;13.

55. Open Code 4.0. University of Umeå, Sweden: ICT Services and System Development and Division of Epidemiology and Global Health. 2013.

56. Parhiala P, Ranta K, Gergov V, Kontunen J, Law R, La Greca AM, Torppa M, Marttunen M. Interpersonal counseling in the treatment of adolescent depression: a randomized controlled effectiveness and feasibility study in school health and welfare services. Sch Mental Health. 2019;18:1-9.

57. Balachandran JS, Yu X, Wroblewski K, Mokhlesi B. A brief survey of patients' first impression after CPAP titration predicts future CPAP adherence: a pilot study. J Clin Sleep Med. 2013;9(3):199-205. 
58. Mufson L, Rynn M, Yanes-Lukin P, Choo TH, Soren K, Stewart E, Wall M. Stepped care interpersonal psychotherapy treatment for depressed adolescents: a pilot study in pediatric clinics. Adm Policy Mental Health Mental Health Serv Res. 2018;45(3):417-31.

59. Pu J, Zhou X, Liu L, Zhang Y, Yang L, Yuan S, Zhang H, Han Y, Zou D, Xie P. Efficacy and acceptability of interpersonal psychotherapy for depression in adolescents: a meta-analysis of randomized controlled trials. Psychiatry Res. 2017;253:226-32.

60. Bledsoe SE, Wike T, Killian-Farrell C, Lombardi B, Rizo C, Bellows AM, Sommers AR, Sheely AL. Feasibility of treating depression in pregnant adolescents using brief interpersonal psychotherapy. Soc Work Ment Health. 2018;16(3):252-65.

61. Cuijpers P, Reynolds CF III, Donker T, Li J, Andersson G, Beekman A. Personalized treatment of adult depression: medication, psychotherapy, or both? A systematic review. Depress Anxiety. 2012;29(10):855-64.

62. Fournier JC, DeRubeis RJ, Shelton RC, Hollon SD, Amsterdam JD, Gallop R. Prediction of response to medication and cognitive therapy in the treatment of moderate to severe depression. J Consult Clin Psychol. 2009;77(4):775.

63. Ricou M, Marina S, Vieira PM, Duarte I, Sampaio I, Regalado J, Canário C. Psychological intervention at a primary health care center: predictors of success. BMC Fam Pract. 2019;20(1):1-8.

64. Forde F, Frame M, Hanlon P, MacLean G, Nolan D, Shajahan P, Troy E. Optimum number of sessions for depression and anxiety. Nurs Times. 2005;101(43):36-40

65. Ravitz P, McBride C, Maunder R. Failures in interpersonal psychotherapy (IPT): factors related to treatment resistances. J Clin Psychol. 2011;67(11):1129-39.

\section{Publisher's Note}

Springer Nature remains neutral with regard to jurisdictional claims in published maps and institutional affiliations.
Ready to submit your research? Choose BMC and benefit from:

- fast, convenient online submission

- thorough peer review by experienced researchers in your field

- rapid publication on acceptance

- support for research data, including large and complex data types

- gold Open Access which fosters wider collaboration and increased citations

- maximum visibility for your research: over 100M website views per year

At BMC, research is always in progress.

Learn more biomedcentral.com/submissions 